\title{
Changes in the volume of Sertoli cells during the cycle of the seminiferous epithelium in the rat*
}

\author{
H. P. Bugge $†$ and L. Plöen \\ Department of Anatomy and Histology, Faculty of Veterinary Medicine, \\ Swedish University of Agricultural Sciences, Uppsala, Sweden
}

\begin{abstract}
Summary. Volume density of Sertoli cells in mature rats was estimated in different stages of the cycle of the seminiferous epithelium. Manual point-counting on electron micrograph montages revealed a more than $40 \%$ increase in Sertoli cell volume from just before to just after spermiation. It is suggested that this variation should be considered in studies of stage-dependent cyclic variations in activity of Sertoli cells and/or germ cells.
\end{abstract}

\section{Introduction}

The presence of definite and consistently recurring patterns in the mammalian seminiferous tubule has been known for a long time (Roosen-Runge, 1962). Much attention has been paid to possible cyclic variations in Sertoli cell function (Parvinen, 1982). The introduction of a transillumination technique for identification of the stages of the cycle of the seminiferous epithelium in the rat (Parvinen \& Vanha-Perttula, 1972) made it possible to isolate different stages in unfixed tissue and hence to study selected stages in vitro. A large number of studies has been published recently based on this technique (Parvinen, 1982). In most instances the results are expressed per unit weight of tissue or per unit weight of protein, not taking into consideration that the relative volume of germ cells or Sertoli cells might vary with the stage of the cycle as shown at the light microscopical level (Roosen-Runge, 1955). The aim of the present study was to investigate, at the ultrastructural level, whether the volume density of rat Sertoli cells varies with the stage of the cycle of the seminiferous epithelium.

\section{Materials and Methods}

Animals and fixation procedure. Four male Sprague-Dawley rats, all 126 days of age, weighing $430-490 \mathrm{~g}$ were used. Under general anaesthesia, the left scrotum, inguinal canal and abdomen were opened and the testicular artery dissected free. A small plastic catheter was inserted into the artery and, using a peristaltic pump, the testis was perfused briefly with a Ringer's solution followed by a solution of $5 \%$ glutaraldehyde in $0.067 \mathrm{M}$-cacodylate buffer (pH 7.2) for $20 \mathrm{~min}$. Tissue blocks were post-fixed in osmium tetroxide, dehydrated in ethanol and embedded in Epon.

Selection of preparations and microscopy. From each rat 20-30 blocks were selected at random, and one toluidine-stained section was made from each. On the sections, regular circular or elliptical tubular profiles were examined and classified in stages according to Leblond \& Clermont (1952). Three groups were used: one comprising stages I-II, one stages VI-VII, and one stages IX-XI. The blocks were then trimmed to the level where only one tubular profile remained, with each animal being represented by at least 5 preparations from each stage-group. New semithin sections were cut

\footnotetext{
* Reprint requests to Dr L. Plöen, Department of Anatomy and Histology, P.O. Box 7011, S-75007 Uppsala, Sweden. $\dagger$ Permanent address: Norwegian College of Veterinary Medicine, Department of Anatomy, Oslo, Norway.
} 


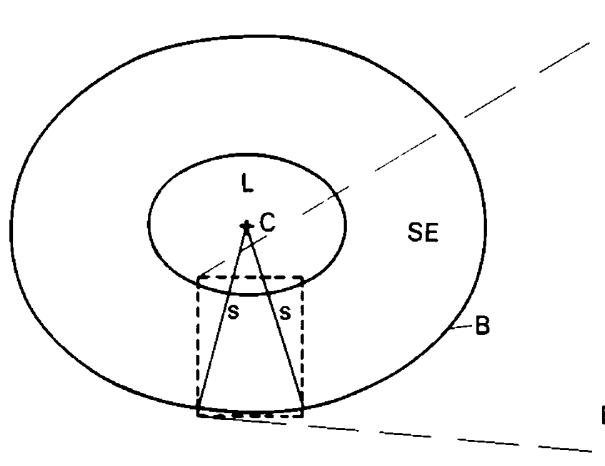

Light micrograph

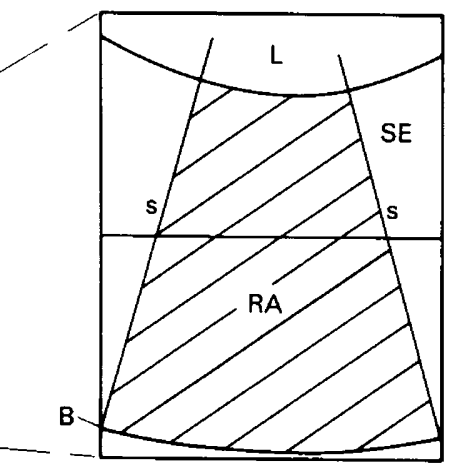

Electron micrograph

Fig. 1. Schematic drawing to show how the reference area was defined. $L=$ lumen of seminiferous tubule. $\mathrm{SE}=$ seminiferous epithelium, $\mathrm{B}=$ basal lamina of seminiferous epithelium, $\mathrm{C}=$ centre of circular/elliptical section, $\mathrm{s}=$ legs of sector, and $\mathrm{RA}=$ reference area.

adjacent to these ultrathin sections. The latter were mounted on 100-mesh grids and contrasted with lead and uranyl salts. The semithin sections were photographed and prints were made to a final enlargement of about 500 diameters. Ultrathin sections were observed under the electron microscope and on each grid a field was selected where the entire width of the seminiferous epithelium was visible. This field was covered by a series of negatives, primary magnification $\times 1200$, and a montage of prints was made, final magnification 6000 diameters.

Morphometry. A major part of the Sertoli cell volume is located in the basal regions of the seminiferous epithelium. Relatively more of the volume of the tubular wall is found near the basement membrane than in the luminal regions. Consequently, great care was taken in selecting the reference area(s) randomly for estimating volume density. As it was not possible to cover entire tubular sections in the electron microscope, representative parts of the tubular walls in the form of sectors were selected and defined as follows (Fig. 1). The part of the seminiferous epithelium covered by the montage of electron micrographs was located on the photomicrograph of the adjacent semithin section. Here, a sector was defined with the apex in the centre of the circle/ellipse and with legs within the area covered by the electron micrographs. This sector was then transferred back to the electron micrograph montage, thereby defining the reference area. It can be mathematically proven that the ratio between basal and luminal areas in such a sector is the same as for the entire section, be it circular or elliptical. Volume density calculations were carried out on the electron micrographs by manual point counting, using a double square grid, ratio 1:9. The distance between the fine points was $2 \mathrm{~cm}$ and the total number of fine points counted in Sertoli cells per animal and stage-group was about 200 (Weibel, 1979). Tubular diameter and epithelial height were measured directly on the light micrographs, all of which were printed at the same magnification. Since no corrections for shrinkage, for example, were made, and the absolute values were not relevant to this study, the values are expressed in $\mathrm{cm}$ on the micrographs. Epithelial height was measured from the basal lamina to the luminal border along a randomly drawn radius in circular profiles, and along the short axis in elliptical profiles.

Statistics. Statistical analysis was based on means of values from one animal and stage-group. The values from one stage-group were compared to corresponding values from another stagegroup within the same animal, hence a $t$ test for paired comparisons was applied. 


\section{Results}

In stages IX-XI the volume density of Sertoli cells was significantly greater than in stages I-II $(P<0.025)$ or VI-VII $(P<0.05)$, whereas there was no significant difference between the two latter groups (Table 1). The tubular diameter seemed larger in stages VI-VII than in stages I-II or IX-XI, but the differences were not significant. Epithelial height was less in stages VI-VII than in stages I-II $(P<0.005)$ or IX-XI $(P<0.05)$ (Table 2$)$.

Table 1. Volume density of Sertoli cells in the seminiferous epithelium based on calculations from point counting on electron micrographs (magnification $\times 6000$ )

\begin{tabular}{lccc}
\hline & \multicolumn{3}{c}{ Volume density of Sertoli cells in stages: } \\
\cline { 2 - 4 } Animal & I-II & VI-VII & IX-XI \\
\hline A & $0 \cdot 25$ & 0.27 & 0.32 \\
B & $0 \cdot 25$ & 0.22 & 0.38 \\
D & $0 \cdot 28$ & 0.23 & 0.32 \\
E & $0 \cdot 23$ & 0.25 & 0.34 \\
Mean \pm s.d. & $0.25 \pm 0.02$ & $0.24 \pm 0.02$ & $0.34 \pm 0.03$ \\
\hline
\end{tabular}

Significant differences between stages I-II and IX-XI $(P<0.025)$ and between stages VI-VII and IX-XI $(P<0.05)$.

Table 2. Tubular diameter, epithelial height, epithelial area and volume density of Sertoli cells in the different stages of the seminiferous tubule cycle

\begin{tabular}{|c|c|c|c|c|}
\hline Stages & $\begin{array}{c}\text { Tubular } \\
\text { diam } \\
\text { (cm)* }\end{array}$ & $\begin{array}{c}\text { Epithelial } \\
\text { height } \\
(\mathrm{cm})^{*}\end{array}$ & $\begin{array}{c}\text { Epithelial area } \\
\text { of perpendicularly } \\
\text { sectioned tubules } \\
\left(\mathrm{cm}^{2}\right)^{*}\end{array}$ & $\begin{array}{l}\text { Volume density } \\
\text { of Sertoli cells }\end{array}$ \\
\hline $\begin{array}{l}\text { I-II } \\
\text { VI-VII } \\
\text { IX-XI }\end{array}$ & $\begin{array}{l}13.4 \pm 0.3 \\
13.9 \pm 0.6 \\
13.3 \pm 0.8\end{array}$ & $\begin{array}{l}4 \cdot 6 \pm 0.5 \\
3 \cdot 9 \pm 0.5 \\
4 \cdot 6 \pm 0.3\end{array}$ & $\begin{array}{l}125 \cdot 1 \pm 10 \cdot 2 \\
121 \cdot 2 \pm 14 \cdot 5 \\
124 \cdot 4 \pm 11 \cdot 6\end{array}$ & $\begin{array}{l}0.25 \pm 0.02 \\
0.24 \pm 0.02 \\
0.34 \pm 0.03\end{array}$ \\
\hline
\end{tabular}

The values are mean \pm s.d. for 4 rats ( 20 tubules per stage group).

*On photomicrographs (magnification $\times 500$ ).

\section{Discussion}

The present results show that there is a more than $40 \%$ increase in volume density of Sertoli cells from a stage just before to a stage just after spermiation (Table 1). Since volume density is a relative value the observed increase might have been due to a decrease in reference volume rather than a true increase in Sertoli cell volume. Such a possibility can be ruled out if it can be shown that the reference volume does not change significantly. Thus tubular diameter and epithelial height were also measured, and from these measurements the epithelial area of perpendicularly sectioned tubules was calculated and found not to vary significantly (Table 2). The number of Sertoli cells per unit length of a tubule shows no stage variations (Wing \& Christensen, 1982). Consequently the 
reference volume is fairly similar between the stages and hence the observed changes in volume density of Sertoli cells must be interpreted as reflecting true changes in volume. This increase is probably, at least in part, a result of the phagocytosis of residual bodies that takes place in close relation to spermiation. In a light microscopic study, Roosen-Runge (1955) found stage-dependent variations in Sertoli cell volume. In contrast to our results he found that the relative Sertoli cell volume was highest before spermiation, but the relative volumes of Sertoli cells in different stages were much lower than in the present study. As pointed out by Roosen-Runge (1955) the thin Sertoli cell extensions are beyond the resolution of the light microscope which may account for the different results.

Cavicchia \& Dym (1977) studied electron microscopically the relative volume of monkey (Macaca mulatta) Sertoli cells in stage I and stage VII (just after spermiation, i.e. corresponding to stage IX in the rat); they reported volume changes that were very similar to those obtained in the present study.

Wing \& Christensen (1982) found stage-dependent variations in tubular diameter and epithelial volumes of rats, both diminishing after spermiation. If the values in their study are combined with our values on Sertoli cell volume density, a true increase in the volume of the Sertoli cells is obtained from stages VI-VII to stages IX-XI. The fact that no significant variation in tubular diameter was found in the present study may, at least in part, be due to the limited number of such measurements; an insignificant difference was actually observed.

The stage-dependent variation in Sertoli cell volume density indicates that the ratio between absolute volumes (and weights) of Sertoli cells and germ cells varied significantly between different stages of the cycle of the seminiferous epithelium. Such variations ought to be considered in studies of stage-dependent cyclic variations of Sertoli cell and/or germ cell activities.

This study was supported by grants from the Swedish Council for Forestry and Agricultural Research. We thank H. Ekwall, $\AA$. Jansson and B. Hellmén for excellent technical assistance.

\section{References}

Cavicchia, J.C. \& Dym, M. (1977) Relative volume changes of Sertoli cells in monkey seminiferous epithelium: a stereological analysis. Am. J. Anat. 150, 501-507.

Leblond, C.P. \& Clermont, Y. (1952) Definition of the cycle of the seminiferous epithelium in the rat. Ann. N. Y. Acad. Sci. 55, 548-573.

Parvinen, M. (1982) Regulation of the seminiferous epithelium. Endocr. Rev. 3, 404-417.

Parvinen, M. \& Vanha-Perttula, T. (1972) Identification and enzyme quantitation of the stages of the seminiferous wave in the rat. Anat. Rec. 174, 435-450.
Roosen-Runge, E.C. (1955) Quantitative studies on spermatogenesis in the albino rat. III. Volume changes in the cells of the seminiferous tubules. Anat. Rec. 123, 385-398.

Roosen-Runge, E.C. (1962) The process of spermatogenesis in mammals. Biol. Rev. 37, 343-377.

Weibel, E.R. (1979) Stereological Methods; vol. 1: Methods for Biological Morphometry. Academic Press, London.

Wing, T.-Y. \& Christensen, A.K. (1982) Morphometric studies on rat seminiferous tubules. Am. J. Anat. 165, 13-25. 